\title{
Membranas de Poli (Ácido Lático-Co-Ácido Glicólico) como Curativos para Pele: Degradação In Vitro e In Vivo
}

\author{
Camila A. Rezende \\ Instituto de Química, UNICAMP \\ Carolina Luchesi, Maria de Lourdes P. Barbo, Eliana A. R. Duek \\ Centro de Ciências Médicas e Biológicas, PUC-SP
}

Resumo: O poli (ácido lático-co-ácido glicólico) é um copolímero biodegradável e bioreabsorvível. Suas propriedades físico-químicas têm sido estudadas com o intuito de modular sua suscetibilidade à degradação e suas interações com células e fluidos biológicos para aplicações na área médica e odontológica. Neste trabalho, membranas de poli (ácido lático-co-ácido glicólico) com e sem plastificante foram preparadas pela técnica de evaporação do solvente e caracterizadas in vitro e in vivo. Os resultados in vitro mostraram que a adição de plastificante diminui a temperatura de transição vítrea ( $\mathrm{Tg}$ ) das membranas e, conseqüentemente, aumenta a flexibilidade das mesmas. Com o avanço da degradação, verifica-se o aparecimento de regiões cristalinas e de poros. Os estudos in vivo mostraram que o polímero degradou rapidamente em contato com a pele sem causar inflamações sérias e protegeu a área ulcerada da ação de agentes externos. Além disso, a cicatrização das feridas foi mais rápida na presença das membranas mostrando que as mesmas podem ser potencialmente utilizadas como curativos para pele.

Palavras-chave: Poli (ácido lático-co-ácido glicólico), degradação in vivo, degradação in vitro, cicatrização, membrana.

\section{Poly (lactide-co-glycolide) membranes as skin repair: in vitro and in vivo degradation}

Abstract: Poly (lactide-co-glycolide) is a polymer with bioabsorption and biodegradation properties. The physical and chemical properties of this polymer have been studied in order to modulate its susceptibility to degradation and its interaction with cells and biological fluids, aiming at medical and dental applications. In this work, membranes of poly (lactide-coglycolide) with and without plasticizer were prepared by solvent evaporation and characterized by in vitro and in vivo experiments. In vitro studies showed that the glass transition temperature decreased due to the addition of plasticizer and, consequently, their flexibility increased. During degradation, crystalline areas and porous appear. In vivo studies showed that the polymer degraded rapidly without causing inflammation and protected areas that were exposed to external agents. Furthermore, membranes improved wound healing time, indicating that they can be potentially used in skin repair.

Keywords: Poly (lactide-co-glycolide), in vivo degradation, in vitro degradation, cicatrisation, membrane.

\section{Introdução}

Os primeiros usos de polímeros in vivo foram em aplicações onde o material mantinha-se inerte durante o tempo do implante e interações indesejadas deviam ser evitadas ou minimizadas. Apesar da prevenção de respostas indesejáveis ainda ser importante para muitas aplicações, novos polímeros capazes de interagir com células para promover crescimento e diferenciação têm sido desenvolvidos ${ }^{[1]}$.

Na classe dos poli ( $\alpha$-hidróxi ácidos) encontram-se muitos exemplos de polímeros bioreabsorvíveis que, após serem implantados no organismo para uma determinada finalidade, são absorvidos pelo mesmo. Exemplos de tais polímeros são o poli (L-ácido lático) (PLLA), o poli (ácido glicólico) (PGA), a poli (p-dioxanona) (PPD), o poli (hidróxi butirato) (PHB), o poli (hidróxi valerato) (PHV) e seus copolímeros.

O poli (L-ácido lático) degrada lentamente gerando unidades cristalinas que podem causar uma resposta longa e prolongada por parte do tecido. Por outro lado, o poli (ácido glicólico) degrada tão rapidamente que se torna inconveniente para a maioria da aplicações. A grande vantagem da utilização do copolímero constituído pelas unidades monoméricas dos dois polímeros é poder variar a proporção entre elas e otimizar o tempo de degradação do material para determinadas aplicações ${ }^{[2]}$.

O processo de degradação do polímero que constitui o implante varia com sua massa molar, sua composição, estória térmica, estrutura cristalina e quantidade de polímero aplicada. Assim, é importante estudar estas propriedades,

Autor para correspondência: Eliana A. R. Duek, Centro de Ciências Médicas e Biológicas, Pontifícia Universidade Católica de São Paulo, Praça Dr. José Ermírio de Moraes 290, CEP: 18030-230, Sorocaba, SP. E-mail: eliduek@fem.unicamp.br 
pois elas determinam o tipo e a intensidade da resposta inflamatória do tecido ${ }^{[2-4]}$.

Membranas densas e porosas de polímeros absorvíveis são obtidas com o intuito de servirem como um substrato para que células isoladas possam fixar-se e crescer até formar o tecido. Este suporte pode agir tanto como apoio físico, quanto como um substrato aderente para as células isoladas durante cultura in vitro ou subseqüente implante para promover a regeneração natural de tecidos, especialmente ossos e cartilagens. Para este tipo de aplicação, é necessária uma matriz tridimensional, mecanicamente estável e com poros interconectados, para que as células possam crescer por toda a estrutura. À medida que as células crescem e se organizam, o polímero degrada e é absorvido pelo organismo, levando a uma substituição natural do tecido ${ }^{[5-11]}$. O poli (ácido láticoco-ácido glicólico), PLGA, é bastante adequado para aplicações como suporte para células ${ }^{[10]}$. Um estudo realizado por Peter e colaboradores mostrou que não ocorre desmineralização do osso durante a degradação do PLGA in vivo ${ }^{[11]}$. Nakamura e colaboradores mostraram que não é observado o aparecimento de tumores após o implante e até o completo desaparecimento do copolímero implantado ${ }^{[12]}$.

Muitas técnicas têm sido empregadas na preparação de membranas porosas de polímeros bioreabsorvíveis: evaporação de solvente utilizando sal com granulometria controla$\mathrm{da}^{[13]}$, inversão de fase ${ }^{[14]} \mathrm{e}$ borbulhamento de gás ${ }^{[15]}$. Luciano e colaboradores mostraram que a adição de plastificante a uma matriz de poli (ácido lático) produz membranas porosas e bioabsorvíveis com poros interconectados de tamanho controlado e com boas propriedades mecânicas para utilização como suporte para cultura de células ${ }^{[16-18]}$.

Além de suporte para células, o PLGA também tem sido estudado para aplicação em sistemas de liberação controlada de drogas no organismo. Neste caso, agentes terapêuticos são formulados dentro de microesferas ou discos do copolímero e a liberação da droga dependerá da degradação do polímero e da difusão da mesma ${ }^{[19,20]}$.

Feridas na pele resultantes de queimaduras e doenças congênitas ou adquiridas são bastante perigosas para os pacientes, particularmente em casos em que a área atingida é extensa, uma vez que o ferimento está sujeito à invasão de bactérias e à perda de fluidos corpóreos. Sob estas condições, o recobrimento rápido e efetivo da ferida é essencial para o tratamento da enfermidade ${ }^{[21]}$. Durante muitos anos, o tratamento convencional para este tipo de problema tem sido o transplante de pele. Contudo, este procedimento é difícil ou mesmo impossível em casos em que a área da ferida é muito grande, por exemplo, em queimaduras muito extensas, devido à inexistência de doadores, à rejeição do material implantado, ao tempo necessário para a total cicatrização e aos riscos envolvidos. Estas dificuldades tornam necessários estudos envolvendo materiais alternativos para proteção e cicatrização de ulcerações na pele, que sejam flexíveis, atóxicos e capazes de aderir adequadamente à área afetada, diminuindo a perda de fluidos e eletrólitos, protegendo contra a proliferação de micróbios e promovendo a cicatrização da ferida ${ }^{[21]}$.
Neste trabalho, membranas de poli (ácido lático-co-ácido glicólico) com e sem plastificante foram preparadas e suas propriedades foram estudadas com o objetivo de avaliar sua aplicação potencial como curativos para ulcerações na pele.

\section{Experimental}

\section{Preparação das membranas}

Foram preparadas membranas com e sem plastificante de dimensões $6 \mathrm{~cm} \times 2 \mathrm{~cm} \times 0,5 \mathrm{~cm}$ utilizando a técnica de evaporação do solvente. O polímero utilizado para preparação das membranas foi o poli (ácido lático-co-ácido glicólico) (50:50, MM $81700 \mathrm{~g} \mathrm{~mol}^{-1}$ ) ( PURAC- Groeningen Holanda).

\section{1) Membranas sem plastificante}

Soluções poliméricas contendo polímero nas concentrações de 5 e $10 \% \mathrm{~m} / \mathrm{V}$ foram preparadas, dissolvendo-se, respectivamente, 0,3 e 0,6 g de PLGA em 5,7 e 5,4 ml de clorofórmio (Merck KgaA, Darmstadt, Alemanha). Após completa dissolução do polímero sob agitação, as soluções foram depositadas em uma placa de vidro e colocadas dentro de uma cuba saturada com vapor de solvente. Após evaporação do solvente durante 24 horas, as membranas foram secas a vácuo por 8 horas e mantidas nesta condição até a caracterização.

\section{2) Membranas com plastificante}

Estas membranas foram preparadas exatamente como as anteriores, exceto pela adição do plastificante trietil citrato de sódio (ALDRICH, Milwaukee, USA) durante a dissolução por agitação.

No total, foram preparados cinco tipos de membranas: PLGA 5\% (5\% de polímero); PLGA 5\%1p (5\% de polímero e $1 \%$ de plastificante); PLGA $10 \%$ (10\% de polímero); PLGA $10 \% 3 \mathrm{p}$ ( $10 \%$ de polímero e $3 \%$ de plastificante) e PLGA $10 \% 5 \mathrm{p}$ ( $10 \%$ de polímero e $5 \%$ de plastificante).

\section{Degradação e caracterização in vitro}

As membranas foram imersas em tampão fosfato $(\mathrm{pH}=7)$, dentro de tubos de ensaio fechados à temperatura de $37^{\circ} \mathrm{C}$ e retiradas após 15, 30, 60 e 120 dias. Ao final de cada período, as membranas foram removidas da solução tampão, lavadas e mantidas em água destilada por 1 hora para remover a maior quantidade possível de solução tampão. Antes e após a degradação, as membranas foram caracterizadas pelas técnicas descritas a seguir.

Calorimetria diferencial de varredura (DSC): aquecimento entre 25 e $200{ }^{\circ} \mathrm{C}$ seguida de isoterma por 5 minutos. Após isto, as amostras foram resfriadas a $-20^{\circ} \mathrm{C}$, mantidas novamente em isoterma por 5 minutos e reaquecidas até $200^{\circ} \mathrm{C}$. Tanto o aquecimento quanto o resfriamento foram realizados em uma taxa de $10^{\circ} \mathrm{C} \mathrm{min}^{-1}$ e o equipamento utilizado foi um DSC 2920 - Modulated DSC (TA Instruments).

Microscopia eletrônica de varredura (MEV): amostras de superfícies de membranas e fraturas (obtidas em nitrogênio líquido) foram metalizadas com ouro (Sputter Coater BAL- 
TEC SCD 050) e analisadas em um microscópio eletrônico de varredura (JEOL JXA 860) operado a $10 \mathrm{kV}$.

Difratometria de raios- $x$ : as análises foram realizadas em ângulos entre 0 e $50^{\circ} \mathrm{em}$ um difratômetro de raios-x Shimadzu $\mathrm{XD} 3 \mathrm{~A}$ com fonte de radiação $\mathrm{CuK} \alpha$. A voltagem utilizada foi de $30 \mathrm{kV}$ e a corrente de $20 \mathrm{~mA}$.

\section{Degradação e caracterização in vivo}

Dois tipos de membranas (10\%3p e 10\%5p) foram implantados. O estudo envolveu 24 ratos Wistar de ambos os sexos com aproximadamente 3 meses de idade e $0,4 \mathrm{~kg}$ de peso. Os ratos foram divididos em 3 grupos de 8 ratos cada. A membrana $10 \% 5$ p foi implantada no primeiro grupo e a $10 \% 3$ p no segundo. No terceiro grupo, a ferida não foi recoberta. A pele normal retirada durante a intervenção cirúrgica foi armazenada em formaldeído e serviu como controle. Durante o período do estudo os ratos receberam ração comercial, água ad libitum e anestésicos antes da cirurgia. A pele e o subcutâneo foram dissecados, removidos até o nível da fascia e as feridas resultantes foram recobertas com pedaços de membranas poliméricas $(2 \mathrm{~cm} \times 2 \mathrm{~cm} \times 0,5 \mathrm{~cm})$. Os implantes foram removidos após 1 , $3,5,7,10,21$ e 30 dias, desidratados e processados para inclusão em parafina. As amostras foram coradas com hematoxilina e eosina (HE) e examinadas em um microscópio ótico NIKON Eclipse E800.

\section{Resultados e Discussão}

\section{Degradação in vitro}

Os valores de temperatura de transição vítrea $(\mathrm{Tg})$ foram obtidos antes e após a degradação para as membranas de PLGA por calorimetria diferencial de varredura (DSC) (curvas de segundo aquecimento). Observando os valores de Tg na Tabela 1, é possível verificar que as membranas com plastificante apresentam valores de Tg sempre menores que as membranas de mesma concentração às quais o plastificante não foi adicionado. No entanto, este efeito é predominantemente observado antes do início do processo de degradação ou no início do processo (15 dias). Com 30 e 60 dias de degradação, os valores de $\mathrm{Tg}$ tanto para as membranas com plastificante quanto para as que não o contém tornam-se muito semelhantes. Um outro comportamento que também pode ser observado é a diminuição nos valores de $\mathrm{Tg}$ das membranas sem plastificante à medida que avança o tempo de degradação, o que pode ser explicado pela diminuição de massa molar que ocorre durante a degradação pela quebra das cadeias poliméricas. Para as membranas com plastificante, praticamente não se nota variação nos valores de $\mathrm{Tg}$ à medida que a degradação ocorre. Isso acontece, provavelmente, devido à ação de dois efeitos de ação contrária: a saída de plastificante que difunde para a solução provocando aumento na $\mathrm{Tg}$ e a perda de massa molar do polímero em conseqüência do processo de degradação, que diminui a Tg.

Antes da degradação e nos estágios iniciais (até 30 dias) apenas as temperaturas de transição vítrea aparecem nos termogramas em temperaturas aproximadamente entre $20 \mathrm{e}$ $40{ }^{\circ} \mathrm{C}$, indicando que o polímero é amorfo (Figura 1a-e). Com
Tabela 1. Temperatura de transição vítrea $(\mathrm{Tg})\left({ }^{\circ} \mathrm{C}\right)$ para as membranas de PLGA em função do tempo de degradação, obtidos por DSC (2은 aquecimento).

\begin{tabular}{ccccc}
\hline \multirow{2}{*}{$\begin{array}{c}\text { Membranas de } \\
\text { PLGA }\end{array}$} & \multicolumn{4}{c}{ Tempo de degradação } \\
\cline { 2 - 5 } & zero & $\mathbf{1 5}$ dias & 30 dias & 60 dias \\
\hline $5 \%$ & 44 & 40 & 26 & 21 \\
$5 \% 1 \mathrm{p}$ & 18 & 26 & 26 & 23 \\
$10 \%$ & 46 & 40 & 16 & $* * *$ \\
$10 \% 3 \mathrm{p}$ & 11 & 23 & 14 & 15 \\
$10 \% 5 \mathrm{p}$ & 12 & 18 & 21 & 15 \\
\hline
\end{tabular}

*** Não aparece na curva

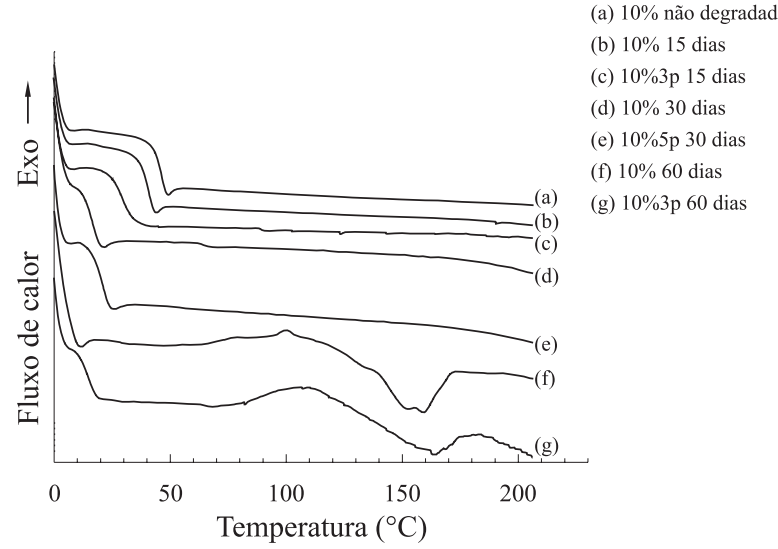

Figura 1. Termogramas de DSC obtidos para as membranas de PLGA: (a) $10 \% 5$ p - não degradada; (b) 10\% - 15 dias; (c) 10\%3p - 15 dias; (d) $10 \%$ -30 dias; (e) $10 \% 5 p-30$ dias; (f) $10 \%-60$ dias; (g) $10 \% 3 p-60$ dias.

60 dias de degradação, nas amostras com concentração de polímero em $10 \%$, há o aparecimento de um discreto pico endotérmico em torno de $150{ }^{\circ} \mathrm{C}$, o que é um indicativo de que está ocorrendo cristalização do polímero durante o processo de degradação. Li e colaboradores observaram um comportamento similar estudando a degradação in vitro de poli (D,L-ácido lático) em pH 3,4 e 7,4 e temperaturas de 37 e $60{ }^{\circ} \mathrm{C}$. Inicialmente, o polímero apresenta um comportamento

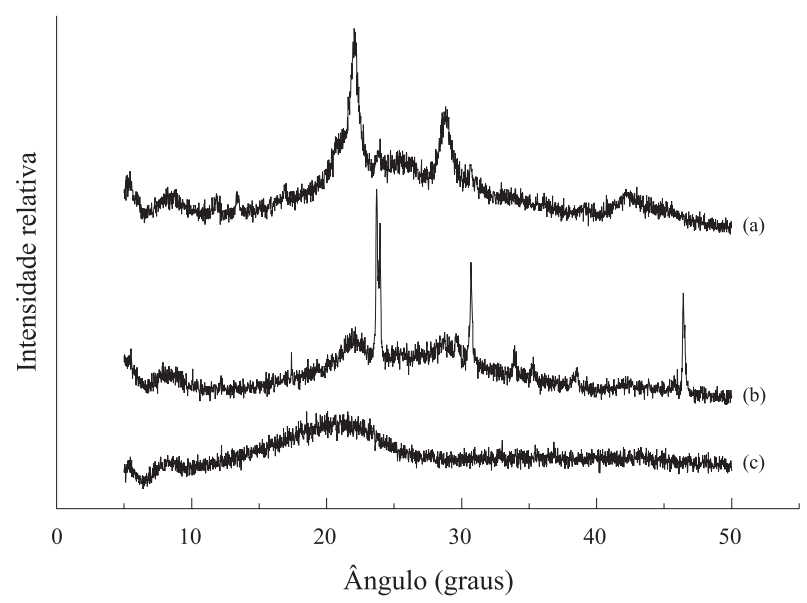

Figura 2. Difratogramas de raios-x obtidos para as membranas de PLGA: (a) $10 \% 5$ p - 120 dias; (b) 10\%5p 60 dias; (c) 10\%5p antes da degradação. 

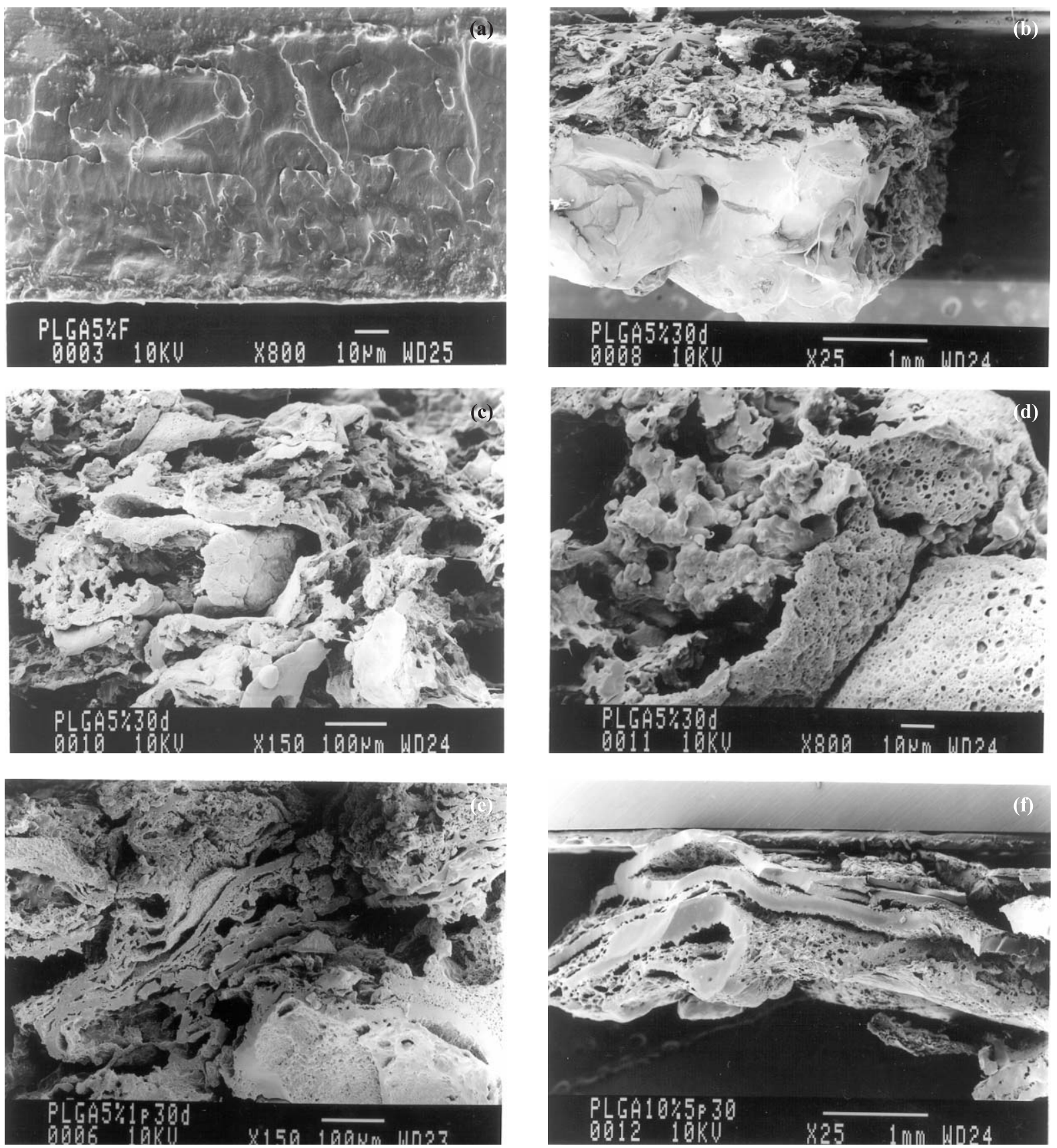

Figura 3. Micrografias de fraturas de membranas de PLGA antes e após a degradação: (a) PLGA 5\% antes da degradação; (b, c, d) PLGA 5\% - 30 dias; (e) PLGA 5\%1p-30 dias; (f) PLGA 10\%5p-30 dias.

tipicamente amorfo e, à medida que o processo de degradação avança, aparecem picos endotérmicos nas curvas de DSC e picos no difratograma referentes à formação de regiões cristalinas ${ }^{[22]}$. A cristalinidade contribui para aumentar o tempo de degradação das membranas fazendo com que elas permaneçam no implante por mais tempo.

Na Figura 2, encontram-se os difratogramas de raios-x para a membrana PLGA $10 \% 5$ p antes e após 60 e 120 dias de degradação. Pode-se observar uma banda larga com intensidade máxima em torno de 20 graus para a membrana (curva c) antes da degradação. Este mesmo comportamento foi observado em todas as membranas não-degradadas, independente da concentração de polímero ou da presença de plastificante e indica que o copolímero é amorfo.

Após 60 dias de degradação, ocorre a formação de áreas cristalinas e o aparecimento de alguns picos definidos na membrana $10 \% 5 \mathrm{p}$ (curva $\mathrm{b}$ ), que se tornam mais pronunciados após 120 dias de degradação (curva a). Observou-se também o aparecimento de picos no difratograma das membranas $10 \%$ e $10 \% 3$ p após 60 e 120 dias de degradação. Esses resultados indicam o mesmo comportamento já observado a partir da análise térmica: a formação de áreas cristalinas com o avanço do processo de degradação.

$\mathrm{Na}$ Figura 3 encontram-se micrografias de fraturas de membranas em função do tempo de degradação. A membrana 5\% (que se encontra na Figura 3a) apresenta uma 

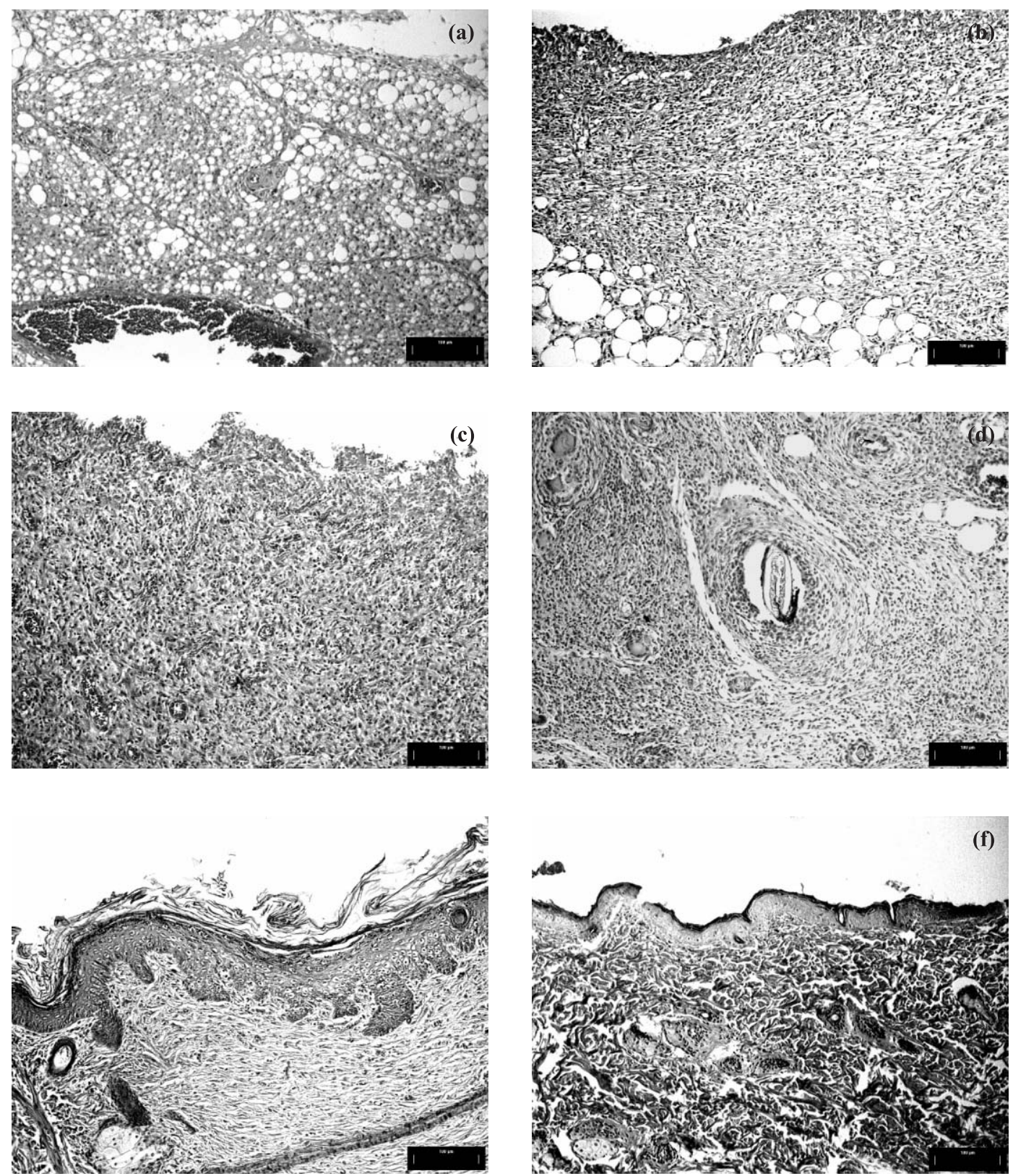

(f)
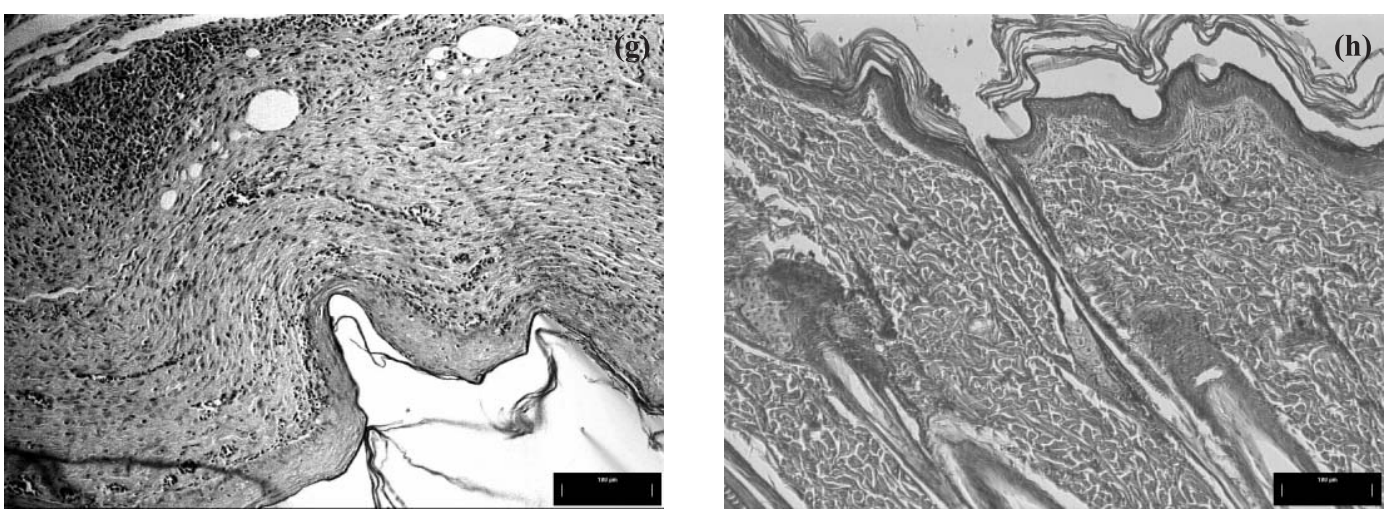

Figura 4. (a) Pele de rato sem membrana implantada (grupo 3) após 3 dias; (b) Pele de rato com implante de membrana 10\%5p (grupo 1) após 5 dias; (c) Pele de rato sem membrana implantada após 5 dias; (d) Pele de rato sem membrana implantada após 10 dias; (e) Pele de rato com implante de membrana 10\%3p após 21 dias; (f) Pele de rato com implante de membrana 10\%5p após 30 dias; (g) Pele de rato sem membrana implantada após 30 dias; (h) Pele de rato normal mostrando os apêndices cutâneos. Barra $=100 \mu \mathrm{m}$. 
morfologia densa antes da degradação. Membranas em todas as concentrações de polímero e plastificante apresentaram o mesmo aspecto denso antes da degradação, sendo que algumas delas eram mais lisas. Após 30 dias de degradação, a membrana $5 \%$ encontra-se em um estado de degradação bastante avançado (Figura $3 b$ ) e sua superfície tem um aspecto bem diferente do de sua superfície de fratura, assim como todas as outras membranas. Após a degradação, as membranas apresentam fraturas bastante características com sulcos, poros e uma aparência fragmentada (Figura 3c-f).

Em um trabalho anterior realizado por este grupo de pesquisa, mostrou-se que a adição do plastificante trietil citrato de sódio a membranas de poli (ácido lático) (PLA) dava origem a uma morfologia com poros interconectados. Os estudos in vivo realizados com este material mostraram que ocorreu uma interação íntima do tecido em crescimento com estas membranas em conseqüência de sua porosidade ${ }^{[16]}$. Assim, neste trabalho com membranas de PLGA, também foi adicionado plastificante ao polímero com o intuito de obter uma morfologia porosa.

No entanto, as membranas de PLGA apresentam um comportamento diferente das de PLA. Independente da presença de plastificante, estas membranas apresentam uma morfologia porosa após a degradação (Figura 3c-f). Este resultado é bastante positivo, já que o crescimento de células depende da presença de poros na matriz-suporte. A formação natural de poros nas membranas de PLGA durante a degradação dispensa procedimentos mais elaborados para a obtenção destes.

Por fim, durante o estudo in vitro foi possível observar que membranas sem plastificante são pouco flexíveis, o que é reflexo dos seus valores de $\mathrm{Tg}$ mais altos em relação às membranas com plastificante. Isso dificulta a sutura das mesmas durante o implante do material e seu contato efetivo com a ferida, tornando sua função protetora menos eficiente. Por outro lado, as membranas com $5 \%$ de polímero são mais finas e rasgam durante a sutura por conterem menor quantidade de material. Dessa forma, foram selecionadas para serem implantadas as membranas $10 \% 3 \mathrm{p}$ e $10 \% 5$ p, que são relativamente mais flexíveis e mais espessas. Além disso, como ocorre formação de áreas cristalinas nas membranas com concentração $10 \%$ durante o processo de degradação, estas membranas possuem um tempo de degradação ligeiramente maior do que as membranas de concentração $5 \%$.

\section{Degradação in vivo}

No primeiro dia após a cirurgia, as feridas sem membrana (grupo 3) apresentavam uma crosta superficial espessa, com infiltrado inflamatório agudo e abundantes neutrófilos polimorfonucleares. Por outro lado, nas feridas em que a membrana foi implantada, não ocorreu a formação da crosta superficial. No terceiro dia, ainda não se observava a formação da crosta nas feridas recobertas, mas apareciam células mononucleares e fibroblastos com escassos abscessos nas bordas da ferida. No grupo 3, onde não foram implantadas membranas, ainda havia infiltrado inflamatório agudo com piócitos, fibrina, restos necróticos e necrose extensa alcan- çando a profundidade da lesão (Figura 4a).

No 5o dia, a pele com implante mostrava um tecido com aspecto reparativo, com organização das fibras de colágeno e escassos granulomas de corpo estranho (Figura 4b). No grupo de controle, a crosta permanecia e o processo inflamatório tinha características mistas com piócitos e início de formação de tecido de granulação (Figura 4c). Nos períodos subseqüentes, evidenciou-se uma reparação mais precoce e organizada nas áreas recobertas pela membrana, enquanto que, no grupo 3, a reparação foi mais irregular com abundantes granulomas de corpo estranho contendo restos de materiais degradados (Figura 4d).

Após 21 e 30 dias, a repitelização foi praticamente total nos três grupos, com maior retração nas áreas recobertas pelas membranas que nos controles. Nos animais com membranas, a remodelação iniciou-se precocemente em comparação com o controle (Figura 4e) e também ocorreu menor reação inflamatória residual (Figuras $4 \mathrm{f}$ e $4 \mathrm{~g}$ ). Comparando os grupos 1 e 2 quanto a alterações inflamatórias e reparativas, não são notadas diferenças significativas entre o comportamento de cada grupo. Em ambos os casos, as cicatrizes apresentam diminuição significativa do número de anexos quando comparadas com as peles controle.

Embora este estudo in vivo seja um projeto piloto e envolva um número pequeno de casos ( 24 casos), foi possível notar diferenças que indicam que o uso destas membranas é promissor na proteção de lesões cutâneas. É importante considerar que as cirurgias foram propositalmente profundas alcançando a fascia, o que dificulta a cicatrização e impede a regeneração de anexos cutâneos. $\mathrm{O}$ retardamento na formação da crosta está relacionado à manutenção da hidratação local pela ação das membranas. O processo inflamatório que se desenvolve após a pele ter sido lesada mostrou ter uma evolução mais rápida e efetiva nas áreas protegidas do que nas sem proteção. Embora o implante de polímeros, por si só, desenvolva uma resposta inflamatória loca ${ }^{[13]}$, não foram detectadas alterações que sugerissem reação inflamatória secundária. Além disso, as membranas propiciaram proteção contra agentes estranhos e traumatismos.

\section{Conclusões}

Os resultados do estudo in vitro mostraram que a Tg das membranas de PLGA diminui como conseqüência da adição de plastificante e do tempo de degradação. Análises de DSC e de difratometria de raios- $\mathrm{X}$ mostraram que, com o avanço da degradação, há o aparecimento de regiões cristalinas nas membranas de PLGA que, inicialmente, eram amorfas. A cristalinidade contribui para uma maior permanência da membrana implantada. Além disso, observou-se a formação de poros durante a degradação, o que proporciona maior interação tecido-matriz.

O estudo in vivo mostrou que as membranas contribuíram para manutenção da hidratação local e levaram a um processo inflamatório mais rápido comparado ao controle. De modo geral, as membranas oferecem boas perspectivas na proteção 
de traumatismos de pequena e média intensidade em queimaduras superficiais e úlceras cutâneas crônicas de difícil tratamento como as que ocorrem em membros inferiores como conseqüência de diabetes, hipertensão e insuficiência vascular. Além disso, o uso destas membranas no recobrimento de grandes superfícies pode melhorar o prognóstico de pacientes, proporcionando proteção nas fases agudas e propiciando melhores condições clínicas para posteriores transplantes de pele.

\section{Agradecimentos}

Os autores agradecem à Fapesp pelo apoio financeiro (processo 99/01381-9).

\section{Referências Bibliográficas}

1. Hench, L. L. - "Bioactive Materials: the Potential for Tissue Regeneration", in: Founders Award, Society for Biomaterials $24^{\text {th }}$ Annual Meeting, San Diego - CA, abril (1998).

2. Van der Elst, M.; Klein, C. P. A. T.; Blieck-Hogervorst, J. M.; Patka, P.; Haarman, H. J. Th. M. - Biomaterials, 20, p. 121 (1999).

3. Ishaugh-Riley, S. L.; Crane, G. M.; Gurlek, A.; Miller, M. J.; Yasko, A. M.; Yaszemski, M. J.; Mikos, A. G. - Journ. of Biomed. Mater. Res., 36, p. 1 (1997).

4. Wake, M. C.; Gerecht, P. D.; Lu, L.; Mikos, A. G. Biomaterials, 19, p. 1255 (1998).

5 . Zoppi, R. A.; Contant, S.; Duek, E. A. R.; Marques, F. R.; Wada, M. L. F.; Nunes, S. P.- Polymer, 40, p. 3275 (1999).

6. Park, J. B. - "Biomaterials: an Introduction", Plenum Press, New York (1979).

7. Hench, L. L. \& Ethridge, E. C. - "Biomaterials: an Interfacial Approach", Academic Press, New York, (1982).

8. Holder, W. D.; Gruber, H. E.; Moore, A. L.; Culberson, C. R.; Anderson, W.; Burg, K. J. L.; Mooney, D. J. - Journ. of Biomed. Mater. Res., 41, p. 412 (1998).
9. Harris, L. D.; Kim, B. S.; Mooney, D. J. - Journ. of Biomed. Mater. Res., 42, p. 396 (1998).

10. Barbanti, S. H.; Santos Jr, A. R.; Zavaglia, C. A. C.; Duek, E. A. R. Journ. Mater. Sci: Mater in Med. No prelo.

11. Peter, S. J.; Miller, M. J.; Yasko, A. W.; Yaszemski M. J.; Mikos, A. G. - Journ. Biomed. Mater. Res., 43, p. 422 (1998).

12. Nakamura, T.; Shimizu, Y.; Takimoto, Y.; Tsuda, T.; Li, Y. H.; Kiyotani, T.; Teramachi, M.; Hyon, S. H.; Ikada, Y.; Nishiya, K. - Journ. Biomed. Mater. Res., 42, p. 475 (1998).

13. Lam, K. H.; Schakenraad, J. M.; Groen, H.; Esselbrugge, H.; Dijkstra, P. J.; Feijen, J.; Nieuwenhuis, P. - Journ. Biomed. Mater. Res., 29, p. 929 (1995).

14. Van de Witte, P.; Esselbrugge, H.; Dijkstra, P. J.; Van den Berg, J. W. A.; Feijen, J. - Journ. of Membrane Sci., 113, p. 223, (1996).

15 . Mooney, D. J.; Baldwin, D. F.; Suh, N. P.; Vacanti, J. P.; Langer, R. - Biomaterials, 17, p. 1417, (1996).

16. Luciano, R. M.; Zavaglia, C. A. C.; Duek, E. A. R.; Alberto-Rincon, M. C. Journ. Mater. Sci: Mater in Med., 14, p. 87, (2003).

17. Silva, D. R. M.; Scapin, S. M. N.; Joazeiro, P. P.; AlbertoRincon, M. C.; Luciano, R. M.; Duek, E. A. R. Journ. Mater. Sci: Mater in Med., 13, p. 327, (2002).

18. Scapin, S. M. N.; Silva, D. R. M.; Luciano, R. M.; Joazeiro, P. P.; Duek, E. A. R.; Alberto-Rincon, M. C. Journ. Mater. Sci: Mater in Med., 14, p. 625, (2003).

19. Choi, S.; Baudys, M.; Kim, S. W. - Pharmaceutical Res., 21, p. 827, (2004).

20. Koushik, K.; Kompella, U. B. - Pharmaceutical Res., 21, p. 524, (2004).

21. Wise, D. L.- "Human Biomaterials Applications", Humana Press Inc, Totowa (1996).

22. Li, S.; McCarthy, S. - Biomaterials, 20, p. 35, (1999).

Enviado: 02/12/04

Reenviado: 29/03/05

Aprovado: 04/04/05 